\title{
Impact of age on early outcome after coronary bypass graft surgery using minimized versus conventional extracorporeal circulation
}

Philipp Kolat ${ }^{*}$, Michael Ried $^{1}$, Assad Haneya ${ }^{2}$, Alois Philipp ${ }^{1}$, Reinhard Kobuch, Stephan Hirt ${ }^{1}$, Michael Hilker ${ }^{1}$, Christof Schmid ${ }^{1}$ and Claudius Diez ${ }^{1}$

\begin{abstract}
Background: Objective of this study was to evaluate the impact of age on comparative early outcomes after coronary artery bypass graft surgery (CABG) with minimized (MECC) and conventional extracorporeal circulation (CECC).

Methods: A retrospective age-, gender- and operation-matched cohort analysis between January 2005 and December 2010 with a total of 2274 patients undergoing CABG with MECC $(n=1137 ; 50 \%)$ or CECC was performed. Patients were stratified into 4 groups according to age: $<59$ years, 60-69 years, 70-79 years, and 80 years of age or older. Outcomes were compared within each age group. Patients with preoperative dialysis were excluded from analysis. Primary endpoint was 30-day mortality.

Results: Patients treated with CECC had a significantly higher mean logistic EuroSCORE (6.3\% vs. 5.0\%; $p<0.001)$, a slightly lower rate of preoperative myocardial infarction ( $46 \%$ vs. $51 \% ; \mathrm{p}=0.01$ ) and a higher rate of impaired renal function (eGFR $<60 \mathrm{~mL} / \mathrm{min} / 1.73 \mathrm{m2}: 24 \%$ vs. 20\%; $p=0.01$ ) compared to MECC-patients. Left internal mammary artery was significantly used more often in MECC patients ( $93 \%$ vs. 86\%; $p<0.001)$. Cardiopulmonary bypass and aortic-cross clamping time were significantly lower in the MECC group $(p<0.001)$. Overall 30-day mortality was significantly higher in patients treated with CECC (4.4\% vs. $2.2 \% ; p=0.002)$. Within the different age groups mortality rates were not significantly different except for patients aged 60-69 years (4.5\% vs. 1.8\%; $p=0.03$ ). Postoperative requirement of renal replacement therapy ( $4 \%$ vs. $2.2 \% ; p=0.01$ ), respiratory insufficiency (9.9\% vs. $6.6 \%$; $P=0.004)$ and incidence of low cardiac output syndrome (3\% vs. 1.2\%; $p=0.003)$ were significantly increased in patients with CECC. Multivariate analysis identified age $(p=0.005 ; 95 \% \mathrm{Cl} 1.01$ to 1.08; OR 1.05) among other parameters as an independent risk factor, whereas conventional extracorporeal circulation itself did not present as an independent risk factor for 30-day mortality.
\end{abstract}

Conclusions: In this matched study sample early outcome was significantly better in patients with MECC compared to CECC, irrespective of age. Prior myocardial infarction estimated GFR $<60 \mathrm{~mL}$ and waiving the use of LIMA were independent risk factors for 30-day mortality, which were more present in the CECC group.

Keywords: Coronary artery bypass grafting, Minimized extracorporeal circulation, Mortality, Outcome

\footnotetext{
* Correspondence: philipp.kolat@ukr.de

'Department of Cardiothoracic Surgery, University Medical Center

Regensburg, Franz-Josef-Strauss Allee 11, 93053 Regensburg, Germany

Full list of author information is available at the end of the article
} 


\section{Background}

Conventional extracorporeal circulation (CECC) is still the gold standard perfusion technique for on-pump coronary artery bypass grafting (CABG). It is world-widely established with standardized proceedings and therefore safe with low related mortality [1-3]. Nevertheless, it is also associated with serious complications such as stroke, hemodilution, coagulopathy, renal dysfunction, and systemic inflammatory response syndrome (SIRS) $[4,5]$.

Beating-heart or off-pump CABG has gained attention as an alternative to myocardial revascularization with CECC over the recent years. Unfortunately, the procedure is technically demanding for cardiac surgeons and preferably used, if not all three coronary vessels must be provided with bypasses [6-8].

Initially, the minimal extracorporeal circulation system (MECC) was developed to facilitate beating heart revascularization, i.e. to maintain the benefits of beating heart surgery and minimize the disadvantages of on-pump revascularization. The MECC system is a closed, fully heparin-coated and pre-connected ECC system, basically consisting of a diffusion membrane oxygenator and a centrifugal pump. The crucial advantage is a higher biocompatibility. It has been proposed that MECC might reduce the harmful effects of CECC, such as systemic inflammatory reaction, hemolysis, hemodilution, disturbances of blood clotting disorders and other postoperative complications. Several authors analyzed the impact of MECC in special patient-cohorts with diabetes, renal insufficiency or in emergent cases [9-11].

The aim of this study was to evaluate the impact of age on comparative early outcomes after coronary artery bypass graft surgery with minimized and conventional extracorporeal circulation.

\section{Methods}

This study was based on a retrospective analysis of 2274 consecutive patients undergoing CABG with MECC $(\mathrm{n}=1137 ; 50 \%)$ or CECC between January 2005 and December 2010 at the Department of Cardiothoracic Surgery, University Medical Center Regensburg, Germany. Whether CECC or MECC was used, was up to the surgeons' preferences and the availability of the perfusion systems.

The study was performed as an age-, gender- and operation-matched cohort analysis. Patients were divided into 4 groups according to age: group $1<59$ years, group $260-69$ years, group $370-79$ years, and group 480 years of age or older. Postoperative outcome was compared within each age group. Patients with preoperative dialysis were excluded from analysis. Primary endpoint of this study was 30-day mortality.

The extracorporeal circuit of the standard ECC consisted of an open system with a non-heparin-coated tube system. A 39-50 F two-stage cannula (Stöckert, Germany) was used to drain the venous blood from the right atrium, a $22 \mathrm{~F}$ aortic cannula (Maquet, Germany) for the distal ascending aorta. The MECC was a closed system with a significantly reduced priming volume without contact of blood with air. The components of the system included a membrane oxygenator (Quadrox D; Maquet, Germany), a centrifugal pump, a table line $(3 / 8$ inch, $180 \mathrm{~cm})$, a venous two-stage cannula (32-40 F) and an aortic cannula (21 F). For further detailed information concerning both systems, we refer to previous publications [12-15].

All operations were performed by senior cardiac surgeons, who were experienced with both, MECC and CECC. The proportion of MECC procedures did not significantly differ between surgeons and all also operated a similar proportion of patients with CECC. The final decision whether to use MECC or not was left to the surgeon.

The statistical analysis was performed using the SPSS 11.0 software (SPSS Inc., Chicago, IL). Data are presented as mean values + their first standard deviation, or, where appropriate and indicated, as median and interquartile range (IQR). Categorical variables are displayed as frequency distributions (n) and simple percentages (\%). Multivariate analysis of statistically significant parameters was used for detection of independent riskfactors for 30-day mortality. A p-value of less than 0.05 was considered significant.

\section{Results}

\section{Demographic data}

Detailed demographic data including co-morbidities can be obtained from Table 1. Patients treated with CECC had a significantly higher mean logistic EuroSCORE (6.3\% vs. $5.0 \% ; \mathrm{p}<0.001)$, with significant lower ejection fraction $(60 \%$ vs. $63 \% ; \mathrm{p}<0.001)$. The MECC group showed a lower rate of atrial fibrillation ( $75 \%$ vs. $44 \%$; $\mathrm{p}=0.002$ ), but a slightly higher rate of preoperative myocardial infarction ( $46 \%$ vs. $51 \% ; \mathrm{p}=0.01$ ). Renal function was more impaired in the CECC-group (estimated GFR $<60 \mathrm{~mL} / \mathrm{min} / 1.73 \mathrm{~m}^{2}$ : $24 \%$ vs. $20 \%$; $=0.01$ ) compared to MECC-patients. Priority for cardiac surgery was homogeneously distributed between the two groups.

\section{Perioperative data}

The number of grafts was significantly higher in patients with MECC ( $\mathrm{p}=0.004)$. Left internal mammary artery was also used more often in MECC patients (93\% vs. $86 \%, \mathrm{p}<0.001)$. Cardiopulmonary bypass- and aorticcross clamping time were significantly lower in the MECC group $(p<0.001)$. Interestingly, there was no difference concerning drainage loss between the two groups (Table 2). 
Table 1 Demographic data

\begin{tabular}{|c|c|c|c|}
\hline Variable & $\begin{array}{l}\text { CECC } \\
(n=1,137)\end{array}$ & $\begin{array}{l}\text { MECC } \\
(n=1,137)\end{array}$ & p-value \\
\hline Male gender [n; \%] & $995(80.4)$ & $995(80.4)$ & 1.00 \\
\hline Age [years] & $67.3 \pm 8.8$ & $67.3 \pm 8.8$ & 1.00 \\
\hline \multicolumn{4}{|l|}{ Age group [n; \%] } \\
\hline$<59($ group 1$)$ & $240(19)$ & $240(19)$ & \multirow[t]{4}{*}{1.00} \\
\hline $60-69$ (group 2) & $440(36)$ & $440(36)$ & \\
\hline $70-79$ (group 3) & 485 (39) & $485(39)$ & \\
\hline$>80$ (group 4) & $72(6)$ & $72(6)$ & \\
\hline Logistic EuroSCORE $[\%, 95 \%$ Cl) & $6.3(5.8$ to 6.6$)$ & $5.0(4.6$ to 5.3$)$ & $<0.001$ \\
\hline Ejection fraction [\%] & $60(47 ; 70)$ & $63(50 ; 70)$ & $<0.001$ \\
\hline Height $[\mathrm{cm}]$ & $171 \pm 8.5$ & $171 \pm 8$ & 0.26 \\
\hline Weight $[\mathrm{kg}]$ & $86 \pm 16$ & $82 \pm 13$ & $<0.001$ \\
\hline Atrial fibrillation [n; \%] & $75(6.1)$ & $44(3.3)$ & 0.002 \\
\hline COPD $[n ; \%]$ & $107(8.6)$ & $94(7.4)$ & 0.24 \\
\hline Active smoker [n; \%] & $387(31)$ & $355(29)$ & 0.35 \\
\hline Preoperative myocardial infarction [n; \%] & $564(46)$ & $627(51)$ & 0.01 \\
\hline Insulin-dependent diabetes mellitus [n; \%] & $148(12)$ & $138(11)$ & 0.57 \\
\hline Diabetic nephropathy [n; \%] & $52(4.2)$ & $47(3.8)$ & 0.68 \\
\hline Serum creatinine $\left[\mathrm{mg} \times \mathrm{dL}^{-1}\right]$ & $1(0.8 ; 1.2)$ & $0.9(0.8 ; 1.1)$ & 0.10 \\
\hline Estimated GFR $\left[\mathrm{mL} \times \mathrm{min}^{-1} \times 1,73 \mathrm{~m}^{-2}\right]$ & $79(62 ; 96)$ & $82(64 ; 100)$ & 0.02 \\
\hline Estimated GFR $<60 \mathrm{~mL} \times \mathrm{min}^{-1} \times 1,73 \mathrm{~m}^{-2}[\mathrm{n} ; \%]$ & $297(24)$ & $243(20)$ & 0.01 \\
\hline Indication for surgery [n; \%] & & & $<0.001$ \\
\hline Elective & $674(55)$ & $588(48)$ & \\
\hline Urgent & $368(30)$ & $496(40)$ & \\
\hline Emergency & $195(16)$ & $153(12)$ & \\
\hline Second cardiac operation [n; \%] & $91(7.4)$ & $14(1.1)$ & $<0.001$ \\
\hline
\end{tabular}

\section{Postoperative mortality and outcome}

Detailed information can be obtained from Table 2. Duration of postoperative mechanical ventilation showed no significant difference between CECC and MECC (although respiratory insufficiency and pneumonia was more common in CECC patients), as well as need for re-sternotomy. Postoperative as well as discharge serum creatinine were significantly lower in the MECC group ( $\mathrm{p}<0.001)$, therefore, need for dialysis was necessary in CECC group more often ( $p=0.01)$, but was not dependant on age.

Low cardiac output syndrome with prolonged inotropic support was more common in CECC patients $(\mathrm{p}=0.003)$. ICU-stay was significantly longer in the CECC group $(\mathrm{p}<0.001)$, but did not have an influence on total hospital-stay $(\mathrm{p}=0.22)$. Overall 30-day mortality was significantly higher in patients treated with CECC (4.4\% vs. $2.2 \%, \mathrm{p}=0.002$ ). Within the groups 1 to 4 , mortality rates were not significantly different except for patients aged $60-69$ years $(4.5 \%$ vs. $1.8 \%$; $p=0.03)$.
Multivariate analysis identified prior myocardial infarction infarction ( $\mathrm{p}=0.001 ; 95 \% \mathrm{CI} 1.47$ to 4.33 ; OR 2.53), estimated GFR $<60 \mathrm{~mL}$ ( $\mathrm{p}=0.001 ; 95 \% \mathrm{CI} 1.41$ to 3.86 ; OR 2.33) and waiving the use of LIMA ( $\mathrm{p}=0.001 ; 95 \%$ CI 1.49 to 4.73; OR 2.65) to be independent risk factors for 30-day mortality, whereas CECC and reoperation itself was not associated with a higher rate (Table 3 ).

\section{Discussion}

Demographic changes over the last decades led to a different patient population, not only for cardiac surgeons. Todays' elderly patients are characterized by multiple, partially severe co-morbidities including hypertension, diabetes, pulmonary diseases, renal insufficiency, obesity as well as peripheral arterial disease (PAD). The informed patient's wish to benefit from high-end medicine is not only a social-economic burden, but also a demanding challenge for cardiac surgeons. The trend is expected to continue [16]. 
Table 2 Peri- and postoperative data

\begin{tabular}{|c|c|c|c|}
\hline Variable & CECC $(n=1,137)$ [group A] & MECC $(n=1,137)$ [group B] & $\mathrm{p}$-value \\
\hline No of grafts [n] & $3(2 ; 3)$ Range $(1-6)$ & $3(2 ; 4)$ Range $(1-6)$ & 0.004 \\
\hline Use of LIMA [n; \%] & $1061(86)$ & $1150(93)$ & $<0.001$ \\
\hline Bypass time $[\mathrm{min}]$ & $93(75 ; 116)$ & $78(60 ; 97)$ & $<0.001$ \\
\hline Aortic cross clamp time [min] & $53(44 ; 66)$ & $47(35 ; 60)$ & $<0.001$ \\
\hline Drainage-loss [mL] & $550(350 ; 800)$ & $550(370 ; 850)$ & 0.33 \\
\hline Resternotomy [n; \%] & $67(5.4)$ & $69(5.6)$ & 0.93 \\
\hline Mechanical ventilation [hours] & $12(9 ; 16)$ & $11(8 ; 15)$ & 0.34 \\
\hline Serum creatinine postoperative $\left[\mathrm{mL} \times \mathrm{min}^{-1} \times 1,73 \mathrm{~m}^{-2}\right]$ & $1(0.9 ; 1.3)$ & $0.9(0.8 ; 1.2)$ & $<0.001$ \\
\hline Serum creatinine at discharge $\left[\mathrm{mL} \times \mathrm{min}^{-1} \times 1,73 \mathrm{~m}^{-2}\right]$ & $1.1(0.9 ; 1.4)$ & $1(0.9 ; 1.3)$ & $<0.001$ \\
\hline Postoperative dialysis [n; \%] & $49(4.0)$ & $27(2.2)$ & 0.01 \\
\hline$<59($ group 1$)$ & $6(2.5)$ & $2(0.8)$ & 0.29 \\
\hline $60-69$ (group 2) & $17(3.9)$ & $8(1.8)$ & 0.10 \\
\hline $70-79$ (group 3) & $20(4.1)$ & $12(2.5)$ & 0.21 \\
\hline$>80$ (group 4) & $6(8.3)$ & $5(6.9)$ & 1.0 \\
\hline Low cardiac output syndrome [n; \%] & $37(3)$ & $15(1.2)$ & 0.003 \\
\hline Central neurologic event [n; \%] & $26(2.1)$ & $16(1.3)$ & 0.16 \\
\hline Respiratory insufficiency [n; \%] & $122(9.9)$ & $82(6.6)$ & 0.004 \\
\hline Reintubation [n; \%] & $36(2.9)$ & $30(2.4)$ & 0.53 \\
\hline Pneumonia [n; \%] & $64(5.2)$ & $42(3.4)$ & 0.04 \\
\hline ICU-stay [days] & $1(1 ; 3)$ & $1(1 ; 2)$ & $<0.001$ \\
\hline Hospitalization [days] & $11(9 ; 14)$ & $11(9 ; 13)$ & 0.22 \\
\hline In-hospital mortality [n; \%] & $51(4.1)$ & $21(1.7)$ & $<0.001$ \\
\hline 30-day mortality [n; \%] & $56(4.5)$ & $27(2.2)$ & 0.002 \\
\hline$\leq 59($ group 1$)$ & $8(3.3)$ & $2(0.8)$ & 0.11 \\
\hline $60-69$ (group 2) & $22(4.5)$ & $8(1.8)$ & 0.03 \\
\hline $70-79$ (group 3) & $20(4.1)$ & $13(2.6)$ & 0.29 \\
\hline$\geq 80$ (group 4) & $8(11.1)$ & $4(5.6)$ & 0.37 \\
\hline
\end{tabular}

Conventional extracorporeal circulation (CECC) is still the preferred perfusion technique for on-pump coronary artery bypass grafting (CABG). It is world-widely established with standardized proceedings and therefore safe with low related mortality [1-3]. The minimal extracorporeal circulation system (MECC) was developed as an aid to beating heart revascularization, i.e., to maintain the benefits of beating heart surgery and minimize the disadvantages of on-pump revascularization. The use of MECC/CECC is controversely discussed, several comparisons between these two systems can be found in the recent literature, including emergency cases, diabetic

Table 3 Multivariate analysis: independent risk-factors for 30-day mortality

\begin{tabular}{llll}
\hline Variable & p-value & Odds ratio & $\mathbf{9 5 \%} \mathbf{C l}$ \\
\hline Preoperative atrial fibrillation & 0.49 & 0.64 & $0.18-2.28$ \\
Preoperative myocardial infarction & 0.001 & 2.53 & $1.47-4.33$ \\
Estimated GFR $\left.<60 \mathrm{~mL} \times \mathrm{min}^{-1} \times 1,73 \mathrm{~m}^{-2}\right]$ & 0.001 & 2.33 & $1.41-3.86$ \\
Second cardiac operation & 0.94 & 0.97 & $0.42-2.24$ \\
CECC & 0.189 & 1.43 & $0.84-2.45$ \\
No LIMA use & 0.001 & 2.65 & $1.49-4.73$ \\
Bypass time [min] & 0.001 & 1.02 & $1.02-1.03$ \\
Aortic cross clamp time [min] & 0.001 & 0.97 & $0.96-0.98$ \\
\hline
\end{tabular}


patients and those with impaired renal function [9-11]. From our knowledge there is currently no analysis of the impact of age. Repeat revascularization occurred more frequently after off-pump CABG than after on-pump CABG [17] and off-pump CABG was associated with a higher rate of incomplete revascularization and an inferior outcome at 1 year [18].

Our trial does not support the assumption that offpump CABG can improve the early outcome in highrisk patients [17].

The EuroSCORE [19], an established method of calculating predicted operative mortality for patients undergoing CABG, was significantly higher in the CECC group accompanied by lower ejection fraction and lower estimated GFR. For safety reasons (unskilled medical assistant, anaesthesiologist or perfusionist), as well as to manage expected high blood loss due to antiplateletagents in large doses, some surgeons decided to use the conventional method, but it was always up to their own preferences. Understandably, that CECC was also used more often for re-operation cases. Interestingly, we found a higher prior myocardial infarction rate in the MECC group. This reflects the fact that it was no matter of preoperative conditions whether CECC or MECC was used. Our data also suggest no significant difference in survival and outcomes in emergency patients who underwent CABG with MECC/CECC. These data are also proven by our group with respect to emergency patients, who underwent CABG with MECC/CECC; no significant difference concerning survival and outcome could be observed [9].

We could present that the MECC group had a greater number of grafts performed. In contrast, Girerd et al. [20] reported that complete revascularization does not seem to improve long-term survival in older patients and suggested that those patients at high operative risk may be considered, when deemed clinically appropriate, for limited coronary revascularization. However, we always aimed at a complete revascularization, including the use of a LIMA. Nevertheless, clamping time as well as bypass time was lower than in the CECC group, due to lacking necessity of a regular reperfusion period.

Acute kidney injury (AKI) is a main complication after on-pump coronary artery bypass graft surgery [13], which is also seen in this study. Postoperative renal function was more impaired in the CECC group with higher serum creatinine levels as well as need for more frequent dialysis. Benedetto et al. could also show that mini-CPB is associated with a lower incidence of AKI (mainly caused by better organ- and tissue perfusion), when compared with conventional $\mathrm{CPB}$ among patients undergoing CABG [13]. This was also observed by Skrabal et al. [21]. Our study group could already prove that MECC is renoprotective in the early postoperative period, but unfortunately cannot prevent AKI [10].
LCOS with need for inotropic support was more common in the CECC group. This can be explained by a higher EuroSCORE and a lower ejection fraction. Therefore, it is not surprisingly that CECC patients had a longer ICU stay than the corresponding matched group.

Interestingly, we could not detect a significant difference concerning the drainage loss. Many studies proposed higher blood loss and the more frequent use of red blood cell concentrates (RBC) when using the standard ECC. This could not be proven in this cohort, possibly due to strict postoperative coagulation regimens on ICU with recurrent activated-clotting-time (ACT)-controls and, if necessary, standardized counteractions. Our study group proved in former publications a significantly lower need for transfusion of RBC and FFP as well as improved blood cell preservation $[9,11,13,14]$.

Multivariate analysis revealed several independent risk factors for 30-day mortality, among them prior myocardial infarction as well as an estimated GFR $<60 \mathrm{~mL}$. Besides, we could also detect bypass-/aortic cross clamp time as well as waiver of LIMA-use as independent IRFs. The use of conventional ECC did not play a role concerning this topic. We conclude that MECC is a safe procedure, although the mechanism why it is associated with lower mortality is still speculative [9].

\section{Limitations}

This study suffers from two main limitations: first, this study is based on a retrospective and non-randomized design. All patients from our institutional database were screened to select and match patients by age, gender and kind of operation. Thus, there may be a risk of selection bias. Furthermore, as patient groups were matched by their chronological age - and not by the severity of illness and the number of co-morbidities, respectively, the impact of age per se cannot be investigated. Thus, pairs could have been also matched according to frailty ("clinical age") of patients - and then, in a second step, the impact of ("chronological") age on early outcomes may be assessed. Second, we caused a bias by the surgeons' own preferences. There is no standard protocol given, if a patient is surely operated with the help of a MECC- or a CECCsystem. Despite its limitations, our study provides valuable data and insight: we could demonstrate that isolated CABG surgery can be safely performed in elderly patients despite of multiple co-morbidities.

\section{Conclusions}

In this matched study sample early outcome was significantly better in patients with MECC compared to CECC, irrespective of age. Prior myocardial infarction, waiver of LIMA-use as well as an estimated GFR $<60 \mathrm{~mL}$ were independent risk factors for 30-day mortality, but not the use of CECC. 


\section{Consent}

Written informed consent was obtained from the patients for the publication of this report and any accompanying images.

\section{Abbreviations}

ACT: Activated clotting time; AKl: Acute kidney injury; CABG: Coronary artery bypass grafting; CECC: Conventional extracorporeal circulation; Cl: Confidence interval; COPD: Chronic obstructive pulmonary disease; CPB: Cardio-pulmonary bypass; ECC: Extracorporal circulation; eGFR: Estimated glomerular filtration rate; FFP: Fresh frozen plasma; ICU: Intensive care unit; IQR: Interquartile range; IRF: Independent risk factor; LCOS: Low cardiac output syndrome; LIMA: Left internal mammary artery; MECC: Minimized extracorporeal circulation; OR: Odds ratio; PAD: Peripheral artery disease; RBC: Red blood cells; SIRS: Systemic inflammatory response syndrome.

\section{Competing interests}

The authors declare that they have no competing interests.

\section{Authors' contributions}

PK and MR gained data, performed statistical analysis and drafted the manuscript. All other authors participated in the design and helped to draft the manuscript. All authors read and approved the final manuscript.

\section{Author details}

${ }^{1}$ Department of Cardiothoracic Surgery, University Medical Center Regensburg, Franz-Josef-Strauss Allee 11, 93053 Regensburg, Germany. ${ }^{2}$ Department of Cardiac and Vascular Surgery, University Medical Center Schleswig Holstein, Arnold-Heller-Straße 3, 24105 Kiel, Germany.

Received: 24 April 2014 Accepted: 4 August 2014

Published: 28 August 2014

\section{References}

1. Penttilä HJ, Lepojärvi MV, Kiviluoma KT, Kaukoranta PK, Hassinen IE, Peuhkurinen $\mathrm{KJ}$ : Myocardial preservation during coronary surgery with and without cardiopulmonary bypass. Ann Thorac Surg 2001, 71:565-571.

2. Gundry SR, Romano MA, Shattuck OH, Razzouk AJ, Bailey LL: Seven-year follow-up of coronary artery bypasses performed with and without cardiopulmonary bypass. Thorac Cardiovasc Surg 1998, 115:1273-1278.

3. Fitzgibbon GM, Kafka HP, Leach AJ, Keon WJ, Hooper GD, Burton JR: Coronary bypass graft fate and patient outcome: angiographic follow-up of 5,065 grafts related to survival and reoperation in 1,388 patients during 25 years. Am Coll Cardiol 1996, 28:616-2.

4. Borst C, Gründemann PF: Minimally invasive coronary artery bypass grafting: an experimental perspective. Circulation 1999, 99:1400-1403.

5. Royston D: The inflammatory response and extracorporeal circulation. J Cardiothorac Vasc Anesth 1997, 11:341-354.

6. Sabik JF, Gillinov AM, Blackstone EH, Vacha C, Houghtaling PL, Navia J, Smedira NG, McCarthy PM, Cosgrove DM, Lytle BW: Does off-pump coronary surgery reduce morbidity and mortality? J Thorac Cardiovasc Surg 2002, 124:698-707.

7. Hannan EL, Wu C, Smith CR, Higgins RS, Carlson RE, Culliford AT, Gold JP Jones RH: Off-pump versus on-pump coronary artery bypass graft surgery: differences in short-term outcomes and in long-term mortality and need for subsequent revascularization. Circulation 2007, 116:1145-1152.

8. Williams ML, Muhlbaier LH, Schroder JN, Hata JA, Peterson ED, Smith PK, Landolfo KP, Messier RH, Davis RD, Milano CA: Riskadjusted short- and long-term outcomes for on-pump versus off-pump coronary artery bypass surgery. Circulation 2005, 112(9 Suppl):-1-366-I-370.

9. Ried M, Haneya A, Kolat P, Philipp A, Kobuch R, Hilker M, Schmid C, Diez C: Emergency coronary artery bypass grafting using minimized versus standard extracorporeal circulation - a propensity score analysis. J Cardiothorac Surg 2013, 8:59.

10. Diez C, Haneya A, Brünger F, Philipp A, Hirt S, Ruppecht L, Kobuch R, Keyser A, Hilker M, Puehler T, Schmid C: Minimized extracorporeal circulation cannot prevent acute kidney injury but attenuates early renal dysfunction after coronary bypass grafting. ASAIO J 2009, 55(6):602-607.

11. Haneya A, Puehler T, Philipp A, Diez C, Ried M, Kobuch R, Hirt SW, Metterlein T, Schmid C, Lehle K: Coronary artery bypass grafting in patients with type 2 diabetes mellitus: a comparison between minimized and conventional extracorporeal circulation. ASAIO J 2011, 57(6):501-506

12. Immer FF, Ackermann A, Gygax E, Stalder M, Englberger L, Eckstein FS, Tevaearai HT, Schmidli J, Carrel TP: Minimal extracorporeal circulation is a promising technique for coronary artery bypass grafting. Ann Thorac Surg 2007, 84:1515-1521.

13. Benedetto U, Luciani R, Goracci M, Capuano F, Refice S, Angeloni E, Roscitano A, Sinatra R: Miniaturized cardiopulmonary bypass and acute kidney injury in coronary artery bypass graft. Surgery Ann Thorac Surg 2009, 88:529-536.

14. Haneya A, Philipp A, Schmid C, Diez C, Kobuch R, Hirt S, Zink W, Puehler T: Minimised versus conventional cardiopulmonary bypass: outcome of high-risk patients. Eur J Cardiothorac Surg 2009, 36(5):844-848.

15. Ried M, Kobuch R, Rupprecht L, Keyser A, Hilker M, Schmid C, Diez C Reduced 30-day mortality in men after elective coronary artery bypass surgery with minimized extracorporeal circulation-a propensity score analysis. BMC Cardiovasc Disord 2012, 16:12-17.

16. Saxena A, Dinh DT, Yap CH, Reid CM, Billah B, Smith JA, Shardey GC, Newcomb AE: Critical analysis of early and late outcomes after isolated coronary artery bypass surgery in elderly patients. Ann Thorac Surg 2011 92(5):1703-1711.

17. Diegeler A, Börgermann J, Kappert U, Breuer M, Böning A, Ursulescu A, Rastan A, Holzhey D, Treede H, Rieß FC, Veeckmann P, Asfoor A, Reents W Zacher M, Hilker M: GOPCABE Study Group Off-pump versus on-pump coronary-artery bypass grafting in elderly patients. N Engl J Med 2013 368(13):1189-1198.

18. Shroyer AL, Grover FL, Hattler B, Collins JF, McDonald GO, Kozora E, Lucke JC, Baltz JH, Novitzky D: Veterans Affairs Randomized On/Off Bypass (ROOBY) Study Group On-pump versus off-pump coronary-artery bypass surgery. N Engl J Med 2009, 361(19):1827-1837.

19. Roques F, Nashef SA, Michel P, Gauducheau E, de Vincentiis C, Baudet E, Cortina J, David M, Faichney A, Gabrielle F, Gams E, Harjula A, Jones MT, Pintor PP, Salamon R, Thulin L: Risk factors and outcome in European cardiac surgery: analysis of the EuroSCORE multinational database of 19030 patients. Eur J Cardiothorac Surg 1999, 15(6):816-822. discussion 822-3.

20. Girerd N, Magne J, Rabilloud M, Charbonneau E, Mohamadi S, Pibarot P, Voisine P, Baillot R, Doyle D, Dumont E, Dagenais F, Mathieu P: The impact of complete revascularization on long-term survival is strongly dependent on age. Ann Thorac Surg 2012, 94:1166-1172.

21. Skrabal CA, Steinhoff G, Liebold A: Minimizing cardiopulmonary bypass attenuates myocardial damage after cardiac surgery. ASAIO J 2007, 53(1):32-35.

doi:10.1186/s13019-014-0143-3

Cite this article as: Kolat et al:: Impact of age on early outcome after coronary bypass graft surgery using minimized versus conventional extracorporeal circulation. Journal of Cardiothoracic Surgery 2014 9:143.

\section{Submit your next manuscript to BioMed Central and take full advantage of:}

- Convenient online submission

- Thorough peer review

- No space constraints or color figure charges

- Immediate publication on acceptance

- Inclusion in PubMed, CAS, Scopus and Google Scholar

- Research which is freely available for redistribution 